\title{
Compositional Analysis of the High Molecular Weight Ethylene Oxide Propylene Oxide Copolymer by MALDI Mass Spectrometry
}

\author{
Orwa Jaber Houshia ${ }^{1} \&$ Charles Wilkins ${ }^{2}$ \\ ${ }^{1}$ Department of Chemistry, Arab American University, Jenin-WestBank, Palestine \\ ${ }^{2}$ Department of Chemistry and Biochemistry, University of Arkansas, 345 N. Campus Drive, Fayetteville, AR \\ 72701, USA \\ Correspondence: Orwa Jaber Houshia, Department of Chemistry, Arab American University, PO box 240, \\ Jenin-WestBank, Palestine. Tel: 972-42-510-801. E-mail: orwa.housheya@aauj.edu
}

Received: March 8, 2012 Accepted: March 31, 2012 Online Published: May 27, 2012

doi:10.5539/ijc.v4n3p14 URL: http://dx.doi.org/10.5539/ijc.v4n3p14

The research was funded by the National Science Foundation grants CHE-00-91868, CHE-99-82045, and CHE-04-5513)

\begin{abstract}
The composition of narrow distribution poly ethylene oxide-propylene oxide copolymer ( $\mathrm{Mw} \sim 8700 \mathrm{Da}$ ) was studied using matrix assisted laser desorption ionization (MALDI) mass spectrometry. The ethylene oxide-propylene oxide copolymer produced oligomers separated by $14 \mathrm{Da}$. The average resolving power over the entire spectrum was 28,000 . Approximately 448 isotopically resolved peaks representing about 56 oligomers are identified. Although agreement between experimental and calculated isotopic distributions was strong, the compositional assignment was difficult. This is due to the large number of possible isobaric components. The purpose of this research is to resolve and study the composition of high mass copolymer such as ethylene oxide-propylene oxide.
\end{abstract}

Keywords: MALDI, mass spectrometry, copolymers, ethylene oxide propylene oxide

\section{Introduction}

The amphiphilic pluronic copolymers, ethylene-oxide propylene-oxide (EO-PO), are of high commercial importance and are used as nonionic surfactants for numerous applications in the pharmaceutical, biomedical, and chemical industries (Kalinoski, 1996; Priorr, 1987; Ryan \& Stanford, 1989). These biodegradable and biocompatible copolymers have the ability to form micelles and hydrogels in water because they consist of a hydrophilic segment, ethylene-oxide, and a hydrophobic segment, propylene-oxide (Alexandridis \& Hatton, 1995; Chu, 1995; Gref et al., 1994; Hamley, 1998; Jeong, Bae, Lee, \& Kim, 1997; Li, Rashkov, Espartero, Manolova, \& Vert, 1996; Schick \& Fowkes, 1996; Tanodekaew, Pannu, Heatley, Attwood, \& Booth, 1997).

By controlling and adjusting the composition of the EO/PO segments in the copolymer, the physical properties of these surfactants can be engineered to fit a desirable application. Because many of the macroscopic physical properties depend on the composition, accurate determination of the composition is an essential part of the copolymer design. A number of techniques are available to characterize the copolymers including NMR, IR, GPC, Raman, and Viscosimetry. These tools give good structural and bulk compositional information about the copolymer. However, mass spectrometry can give detailed information (Maciejczek, Mass, Rode, \& Pasch, 2010; Weidner \& Falkenhagen, 2011).

Mass spectrometry has been extensively applied to copolymer analysis, especially since the matrix-assisted laser desorption/ionization (MALDI) technique was introduced. MALDI mass spectrometry allows for direct elucidation of end groups, molecular weight, and the fine compositional details simultaneously (Montaudo, 1999, 2001, 2002; Montaudo \& Samperi, 1998; Przybilla, Francke, Rader, \& Mullen, 2001; Servaty et al., 1998; van Rooij et al., 1998; Wilczek-Vera, 1996; Wilczek-Vera, Yu, Waddell, Danis, \& Eisenberg, 1999a, 1999b; Yoshida, Yamamoto, \& Takamatsu, 1998; Yu, Vladimirov, \& Frechet, 1999; Zoller \& Johnston, 2000). A single spectrum is often sufficient to give complete information about the copolymer (end groups, repeat units, molecular weight, and compositional details). In particular, MALDI Fourier transform mass spectrometry (FTMS) is able to 
distinguish closely spaced peaks-with isobar separation (Kaufman, Jaber, Stump, Simonsick, \& Wilkins, 2004). MALDI mass spectrometry has become a popular tool for characterizing polymers and copolymers for several reasons. The MALDI process predominantly produces singly charged species, making spectral results simple and easy to interpret. The desorbed high molecular weight ions generally survive desorption without major fragmentation. Challenging nonpolar hydrocarbon polymers such as polyethylene (Jaber \& Wilkins, 2005) can be analyzed which might be difficult or impossible with electrospray source ionization (ESI) techniques. Finally, one can take advantage of solventless MALDI preparation methods for insoluble polymers (Dolan \& Wood, 2004; Marie, Fournier, \& Tabet, 2000; Pruns et al., 2002; Przybilla, Brand, Yoshimura, Rader, \& Mullen, 2000; Skelton, Dubois, \& Zenobi, 2000; Trimpin, Grimsdale, Rader, \& Mullen, 2002; Trimpin, Rouhanipour, Az, Räder, \& Müllen, 2001).

The complimentary technique to MALDI mass spectrometry, ESI, can generate a wealth of information about polymers and copolymers (O'Connor \& McLafferty, 1995; Shi, Hendrickson, Marshall, Simonsick, \& J., 1998). But by far the, most frequent mass spectrometry tool used for polymer and copolymer characterization is MALDI time-of flight (TOF) mass spectrometry (Hanton, 2001; Nielen, 1999; Rader \& Schrepp, 1998). However, the limited mass resolution of TOFMS makes it inadequate and unreliable for compositional analysis of copolymer of high molecular weight. Several EO-PO copolymer analyses have been reported for masses below 5000 Da (Chen, Zhang, Tseng, \& Li, 2000; Jaber \& Wilkins, 2005; Schriemer \& Li, 1996; Terrier, Buchmann, Cheguillaume, Desmazieres, \& Tortajada, 2005; van Rooij et al., 1998). Here, we show that MALDI-FTMS extends the compositional EO-PO copolymer analysis for oligomers with masses up to $9900 \mathrm{Da}$. FTMS provides the resolving power needed to isotopically resolve the oligomers. However, even with high resolution spectra, interpretation of the results is difficult at high masses due to the large number of possible isobaric components. Thus, a correlation function was implemented to match the experimental isotopic distribution with the theoretical one in order to narrow the possible compositional choices. It is worth mentioning molecular weights up to 1.5 million Dalton have been detected by MALDI-TOF, but neither oligomer resolution nor isotopic resolution was reported (Schriemer \& $\mathrm{Li}, 1996$ ).

\section{Experimental Methods}

\subsection{Material and Sample Preparation}

Text Poly (ethylene oxide-propylene oxide, mw 8700) copolymer was purchased from Polysciences, Inc. (Warrington, PA). $\mathrm{NaCl}$ was purchased from Aldrich Chemical Co. (Milwaukee, WI). The matrix, 2,5-dihydroxybenzoic acid (DHB), was obtained from Fluka (Milwaukee, WI). Methanol was obtained from EM Science (Gibbstown, NJ). All reagents were used without further purification. DHB was dissolved in methanol to make a $0.5 \mathrm{M}$ solution. $\mathrm{NaCl}$ was dissolved in water at a concentration of $1.15 \times 10^{-3} \mathrm{M}$. The copolymer was dissolved in methanol to a concentration of $5.0 \mathrm{mg} / \mathrm{ml}$ Deposition of sample on the probe tip was done as follows: $1.0 \mu \mathrm{L}$ of copolymer sample is added and allowed to air dry, followed by addition of $0.2 \mu \mathrm{L}$ of $\mathrm{NaCl}$ solution and a final layer of $2.0 \mu \mathrm{L}$ of DHB matrix solution added. The sample is allowed to air dry.

\subsection{Instrumentation}

MALDI experiments were performed using both a 9.4 Tesla Fourier transform mass spectrometer and a reflectron time-of-flight mass spectrometer. The FTMS instrument is an IonSpec Ultima (Lake Forest, CA) with an external ionization source, utilizing a 9.4-Tesla superconducting magnet. The FTMS is also equipped with an ESI source. A Bruker Reflex III reflectron TOF (Billerica, MA) is used for the MALDI-TOF measurements. A $355 \mathrm{~nm}$ pulsed Nd-YAG laser (New Wave, Inc.) was used with FTMS. For The TOF measurements a $337 \mathrm{~nm}$ pulsed laser N2 laser was used. For the Ultima FTMS, ions are created externally by MALDI and guided into the ICR cell using RF quadrupole ion optics. FTMS spectra were acquired in positive ion mode at a pressure of $\sim 5 \mathrm{x}$ $10^{-10}$ Torr. Each spectrum resulted from pulsing the laser 7 times at the same spot on the sample. Ions were gated into the trapping cell after every 7th laser pulse. Spectra measured with the Bruker Reflex III TOF were measured using a $337 \mathrm{~nm}$ laser while operating in reflectron mode. Each TOF spectrum resulted from 200 laser pulses. The data analysis was handled by an in-house computer software-program copolymer calculator.

\subsection{Data Processing}

A home-made computer program was created to calculate the possible copolymer compositions based on Microsoft EXCEL platform and executed using a Pentium $41.6 \mathrm{GHz}$ computer equipped with $768 \mathrm{MB}$ of RAM memory. The program let us select multiple end groups, multiple cation attachment and up to three copolymer segments. The program calculates all of the possible compositional copolymer combinations and then searches the database of mass tables within a specified mass accuracy interval usually within $\pm 50 \mathrm{ppm}$. 


\section{Results and Discussion}

There have been a limited number of reports on compositional analysis of high molecular weight ( $>5000 \mathrm{Da})$ copolymers by MALDI mass spectrometry. This deficiency derives from the fact that many MS instruments are limited in mass range. Furthermore analyses are often performed by relatively low resolution TOFMS. For example, Figure 1 is a MALDI-TOF spectrum of EO-PO copolymer ( $\mathrm{mw} \sim 8700$ ) acquired in reflectron positive ion mode. The spectrum was the result of the sum of 200 laser pulses on the MALDI target. The inset within Figure 1 shows an expanded mass range from $\mathrm{m} / \mathrm{z} 8820-8880$. The average resolving power was $\sim 400$. Due to this low resolving power, oligimeric resolution was difficult to observe and isotopic resolution impossible. Upon attempting to analyze this copolymer using ESI-FTMS, no signal was detected. The reasons for this are not clear. So, in the present study, the alternative of MALDI-FTMS was employed. Mass peak assignment is easier when spectra are acquired at high resolving power. High field FTMS is capable of yielding isotopically resolved peaks of polymers with masses up to $\mathrm{m} / \mathrm{z} 12,000 \mathrm{Da}$ (Jaber \& Wilkins, 2005). The MALDI-FTMS spectrum shown in Figure 2 was acquired with a 9.4 Tesla FTMS. The spectrum was the result of 7 laser shots on the same spot to generate ions, which were gated into the cell after the 7th pulse. A single transient was transformed after excitation of ions to result in a single spectrum. Under these conditions, the average resolving power was about 28000. The mass envelope of the spectrum extends from $\mathrm{m} / \mathrm{z} 8300$ to 9900 . The mass values of the oligomers detected correspond to $(\mathrm{M}+\mathrm{Na})^{+}$, where $\mathrm{M}$ is $\mathrm{HO}-\left[\left(\mathrm{C} 2 \mathrm{H}_{4} \mathrm{O}\right) \mathrm{m}-\left(\mathrm{C}_{3} \mathrm{H}_{6} \mathrm{O}\right) \mathrm{n}\right]-\mathrm{H}$. The fully resolved isotopic peaks in Figure 3B shows oligomers are separated by 14 mass units. The separation between the oligomers is due to the replacement of one EO unit by one PO unit: $(\mathrm{PO})_{\mathrm{y}+1}+(\mathrm{EO})_{\mathrm{x}-1}$. Mass assignment was difficult even though the peaks were well resolved. To speed up the data analysis, a computer software program copolymer calculator was used. Multiple possible compositional combinations were found for each peak. This was not unexpected since the number of isobaric structures increase as mass increases. In the program, possible compositional combinations that had mass accuracy within $\pm 40 \mathrm{ppm}$ were accepted and those outside this interval were rejected. To narrow down the search, a correlation coefficient function (Equation 1) between the theoretical isotopic distribution (Figure 3A) and experimental results was implemented. Results with correlation coefficients between 0.8 and 1.0 were admissible provided that they had mass accuracy with $\pm 40 \mathrm{ppm}$.

$$
r=\frac{S S_{x y}}{\sqrt{\left(S S_{x x}\right)\left(S S_{y y}\right)}}
$$

Where

$$
\begin{gathered}
S S_{x y}=\frac{\left[\sum x y-\left(\sum x\right)\left(\sum y\right)\right]}{n} \\
S S_{x x}=\sum x^{2}-\frac{\left(\sum x\right)^{2}}{n} \\
S S_{x x}=\sum y^{2}-\frac{\left(\sum y\right)^{2}}{n}
\end{gathered}
$$

Where $\mathrm{x}$ is the intensity from the experimental isotopic distribution, $\mathrm{y}$ is the intensity of the theoretical isotopic distribution and $\mathrm{r}$ is the correlation coefficient. Table 1 illustrates some of the multiple acceptable compositional combinations and their respective mass accuracies and correlation coefficients. Note that high correlation does not imply causality. The only valid conclusion is that a linear trend may exist between the theoretical and the experimental results, but it would incorrect to conclude that a change in "x", for example, causes a change in " $y$ ". Therefore what is being established here is the strength of agreement between theory and experiment.

Now the search has been narrowed down, is it possible to explicitly point to a definite compositional assignment? More detailed scrutiny yields a more revealing and complex picture. To illustrate this, consider the mass 8839.9069 $\mathrm{Da}$ in Table 1. This is the measured mass for the expanded oligomer 
Table 1. The Multiple-isobaric possible compositional combinations and their respective mass accuracy and correlation coefficients

\begin{tabular}{|c|c|c|c|c|c|}
\hline Meas.Jred Mass & Theoretica & on & & Tor & \\
\hline $8825.3771(\mathrm{~A}+1)$ & 8825.9571 & 99 & 69 & 9 & 0.83 \\
\hline $8825.3771(A+1)$ & 8825.7963 & 77 & 98 & $-\theta$ & 0.83 \\
\hline $8825.3771(A+1)$ & 8826.1179 & 121 & 40 & 27 & 0.82 \\
\hline $8825.3771(A+1)$ & 8825.6355 & 55 & 127 & -27 & 0.83 \\
\hline $8839.9069(\mathrm{~A}+1)$ & 8839.9728 & 100 & $\overline{68}$ & $\overline{8}$ & $\overline{0.96}$ \\
\hline $8839.9089(A+1)$ & 8839.812 & 78 & 97 & -11 & 0.97 \\
\hline $8839.9089(A+1)$ & 8840.1336 & 122 & 39 & 26 & 0.85 \\
\hline $8839.9089(A+1)$ & 8839.8512 & 58 & 128 & -29 & 0.97 \\
\hline $8854.9528(A+2)$ & 8854.9918 & 101 & 67 & 4 & 0.88 \\
\hline $8854.9528(A+2)$ & 8854.831 & 79 & 98 & -14 & 0.88 \\
\hline $8854.9528(A+2)$ & 8855.1526 & 123 & 38 & 23 & 0.87 \\
\hline $8854.9528(A+2)$ & 8854.6702 & 57 & 125 & .32 & 0.88 \\
\hline $8868.9548(\mathrm{~A}+2)$ & 8869.0074 & 102 & 68 & 8 & 0.82 \\
\hline $8888.9548(A+2)$ & 8868.8468 & 80 & 95 & -12 & 0.83 \\
\hline $8888.9548(A+2)$ & 8869.1682 & 124 & 37 & 24 & 0.81 \\
\hline $8888.9548(A+2)$ & 8868.6858 & 58 & 124 & -30 & 0.83 \\
\hline
\end{tabular}

Spectrum shown in Figure 4. For this mass the possible compositions are: PO100-EO68, PO78-EO97, PO122-EO39, PO56-EO126. For any of these isobaric compositions, a total of 17 theoretical isotopic peaks should be observed at resolving power of 28,000 as shown in Table 2 . In this table the peak labeled "A" indicates that all carbons are of the $12 \mathrm{C}$ (the monoisotopic peak). The " $\mathrm{A}+1$ " peak indicates that there is there is one $13 \mathrm{C}$ and the rest of the carbons in that peak are $12 \mathrm{C}$, and so on, until "A+16". However, instead of observing 17 isotopic peaks only 12 peaks are seen as shown in the theoretically generated spectrum of Figure 5, due to the fact that some peaks are of very low intensity (see Table 2). Despite the striking similarities between the experimental (Figure 4) and the theoretical (Figure 5) isotopic distributions, intriguing differences are observed. First, the peaks in Figure 4 labeled with asterisks display higher intensity than their counterparts in Figure 5. Second, the shoulder peaks appear (overlapping-not well resolved) and are labeled with downward arrows in Figure 4. These observations raise an important question as to the source or the cause of these discrepancies between the two distributions. We postulate that the distorted experimental distribution in Figure 4 is a direct consequence of the coexistence of all 4 possible compositional outcomes. It is very likely that the presence of several possible compositional outcomes collectively contributing to this oligomer pattern. Confronted with uncertainty in choice of "best" combination, it is not surprising that "best" choice is a matter of probability. In general, the statistical probability of a particular result such as, $\alpha \mathrm{m} \beta \mathrm{n}$ for example, can be expressed in Equation 2 by the most probable outcome:

$$
\rho\left(\alpha_{m} \beta_{n}\right)=\frac{(m+n)}{m ! n !}\left(\frac{m}{m+n}\right)^{m}\left(\frac{n}{m+n}\right)^{n}
$$

Where $\mathrm{m}$ is the number of PO segments and $\mathrm{n}$ is the number of EO segments in the oligomer. As an example, starting with equal quantities of the monomers it can be shown that the most probable result for the combination PO100-EO68, PO78-EO97, PO122-EO39, PO56-EO126 is the one with PO56-EO126 compositional combination (this is the series labeled 182 in Figure 6). This means that

This choice is present at highest concentration and hence, it should seem reasonable that the other 3 possible isobaric compositions are at low concentration and have decreased detectability. Note that these isobaric compositions [POx-22 + EOy+29] differ by 0.16 mass units (Table 2) and it would take an average resolving power of 55000 to separate them. Their presence should not be ignored at all, as this would cause Figure 4 to exhibit dissimilarity to Figure 5. This may well be on the basis that one monomer is more reactive than the other.

\section{Conclusion}

Two new results are achieved here. First, MALDI copolymer mass analysis is shown to be feasible up to mass 9900 Da with meaningful results. Second, accurate mass measurement as a result of the high resolution is evident. However, compositional interpretation of high molecular weight copolymer is still complex, but MALDI-FTMS allows for direct measurements of oligomeric components. Such measurements of oligomeric species were impossible by MALDI-TOF with the resolution that was obtained. One obvious and critical issue for the MALDI-FTMS interpretation is the probable existence of multiple isobaric structures that contribute to 
the complexity in mass assignment. This issue is simplified with a combination of correlation functions and probability functions that help narrow down the search for the composition while retaining accurate information. Nevertheless, for extensive application to copolymers with high mass, the difficulties of analyzing compositions of higher mass copolymers will have to be resolved.

Table 2. An example of the theoretically generated isotopic intensity distribution for the mass starting at $\mathrm{m} / \mathrm{z}$ $8839 \mathrm{Da}$

\begin{tabular}{|c|c|c|c|c|c|}
\hline \multicolumn{2}{|c|}{$(\mathrm{C} 3 \mathrm{H} 6 \mathrm{O}) 100(\mathrm{C} 2 \mathrm{H} 4 \mathrm{O}) 68$} & \multirow{2}{*}{$\frac{\text { Intensity }}{3.38}$} & \multicolumn{2}{|c|}{$(\mathrm{C} 3 \mathrm{H} 6 \mathrm{O}) 78(\mathrm{C} 2 \mathrm{H} 4 \mathrm{O}) 97$} & \multirow{2}{*}{$\frac{\text { Intensity }}{3.62}$} \\
\hline $\mathrm{A}$ & 8838.9681 & & $\bar{A}$ & 8838.8073 & \\
\hline $\mathrm{A}+1$ & 8839.9719 & 16.5 & $A+1$ & 8839.8112 & 17.38 \\
\hline $\mathrm{A}+2$ & 8840.9757 & 41.38 & $\mathrm{~A}+2$ & 8840.8149 & 42.92 \\
\hline$A+3$ & 8841.9793 & 70.86 & $A+3$ & 8841.8185 & 72.49 \\
\hline $\mathrm{A}+4$ & 8842.9827 & 93.14 & $A+4$ & 8842.8219 & 94.14 \\
\hline$A+5$ & 8843.9861 & 100 & $A+5$ & 8843.8253 & 100 \\
\hline $\mathrm{A}+6$ & 8844.9890 & 91.32 & $A+6$ & 8844.8281 & 90.47 \\
\hline$A+7$ & 8845.9923 & 72.87 & $\mathrm{~A}+7$ & 8845.8315 & 71.59 \\
\hline$A+8$ & 8846.9955 & 51.77 & At8 & 8846.8347 & 50.49 \\
\hline$A+9$ & 8847.9983 & 33.26 & $A+9$ & 8847.8374 & 32.23 \\
\hline$A+10$ & 8849.0019 & 19.55 & $A+10$ & 8848.841 & 18.84 \\
\hline$A+11$ & 8850.0046 & 10.61 & $A+11$ & 8849.8437 & 10.18 \\
\hline$A+12$ & 8851.0078 & 5.36 & $\mathrm{~A}+12$ & 8850.8468 & 5.12 \\
\hline$A+13$ & 8852.0109 & 2.53 & $A+13$ & 8851.8499 & 2.41 \\
\hline$A+14$ & 8853.0135 & 1.13 & $A+14$ & 8852.8525 & 1.07 \\
\hline$A+15$ & 8854.0166 & 0.47 & $\mathrm{~A}+15$ & 8853.8556 & 0.45 \\
\hline$A+16$ & 8055.0196 & 0.19 & $\mathrm{~A}+16$ & 8054.8585 & 0.18 \\
\hline \multicolumn{2}{|c|}{$(\mathrm{C} 3 \mathrm{H} 6 \mathrm{O}) 122(\mathrm{C} 2 \mathrm{H} 4 \mathrm{O}) 39$} & Intensity & \multicolumn{2}{|c|}{ (C3 H6 O)56 (C2 H4 O)126 } & Intensity \\
\hline A & 8839.1288 & 3.15 & $\mathrm{~A}$ & 8838.6465 & 3.88 \\
\hline $\mathrm{A}+1$ & 8840.1327 & 15.67 & $A+1$ & 8839.6504 & 18.31 \\
\hline $\mathrm{A}+2$ & 8841.1365 & 39.91 & $\mathrm{~A}+2$ & 8840.6541 & 44.51 \\
\hline $\mathrm{A}+3$ & 8842.1401 & 69.27 & $\mathrm{~A}+3$ & 8841.6577 & 74.16 \\
\hline$A+4$ & 8843.1435 & 92.15 & $A+4$ & 8842.6611 & 95.14 \\
\hline$A+5$ & 8844.147 & 100 & $A+5$ & 8843.6645 & 100 \\
\hline$A+6$ & 884 & 92 & +6 & 6673 & 89.62 \\
\hline$A+7$ & 8846.1532 & 74.18 & $A+7$ & 8845.6706 & 70.33 \\
\hline$A+8$ & 8847.1564 & 53.1 & $A+8$ & 8846.6738 & 49.25 \\
\hline$A+9$ & 8848.1592 & 34.33 & $A+9$ & 8847.6765 & 31.23 \\
\hline$A+10$ & 8849.1628 & 20.3 & $A+10$ & 8848.6801 & 18.16 \\
\hline$A+11$ & 8850.1655 & 11.07 & $\mathrm{~A}+11$ & 8849.6827 & 9.76 \\
\hline$A+12$ & 8851.1688 & 5.62 & $\mathrm{~A}+12$ & 8850.6859 & 4.89 \\
\hline$A+13$ & 8852.1719 & 2.66 & $\mathrm{~A}+13$ & 8851.6889 & 2.29 \\
\hline$A+14$ & 8853.1745 & 1.19 & $A+14$ & 8852.6915 & 1.02 \\
\hline$A+15$ & 8854.1777 & 0.5 & $A+15$ & 8853.6946 & 0.43 \\
\hline$A+16$ & 8855.1806 & 0.2 & $A+16$ & 8854.6975 & 0.17 \\
\hline
\end{tabular}

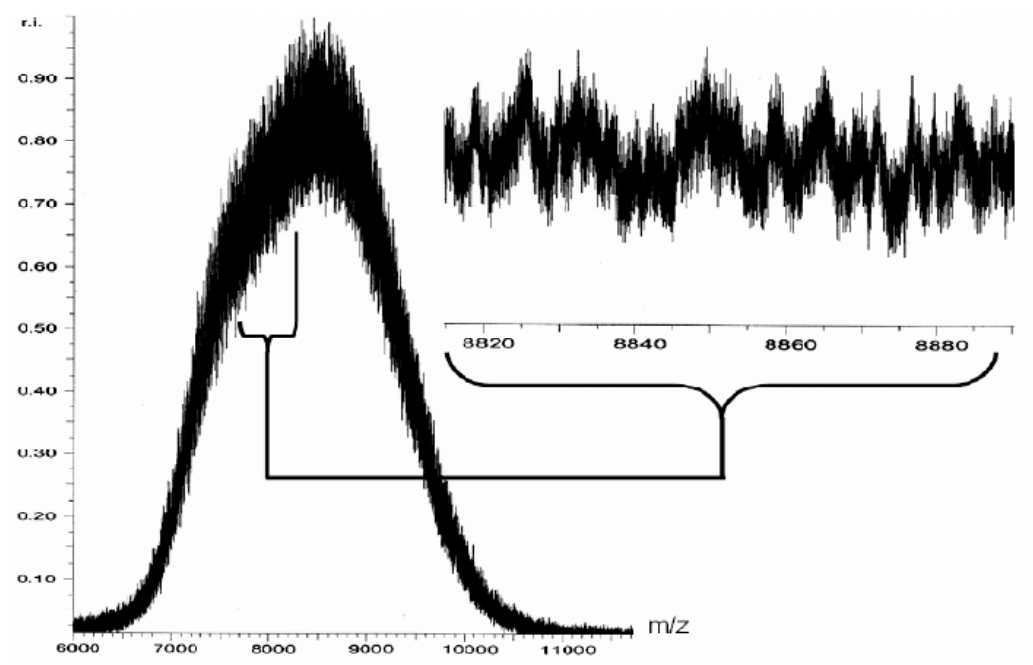

Figure 1. MALDI-TOF spectrum of the EO-PO copolymer with the inset showing an expanded mass range from $\mathrm{m} / \mathrm{z} 8800$ to 8890 ; Compared to that of the expanded FTMS spectrum 


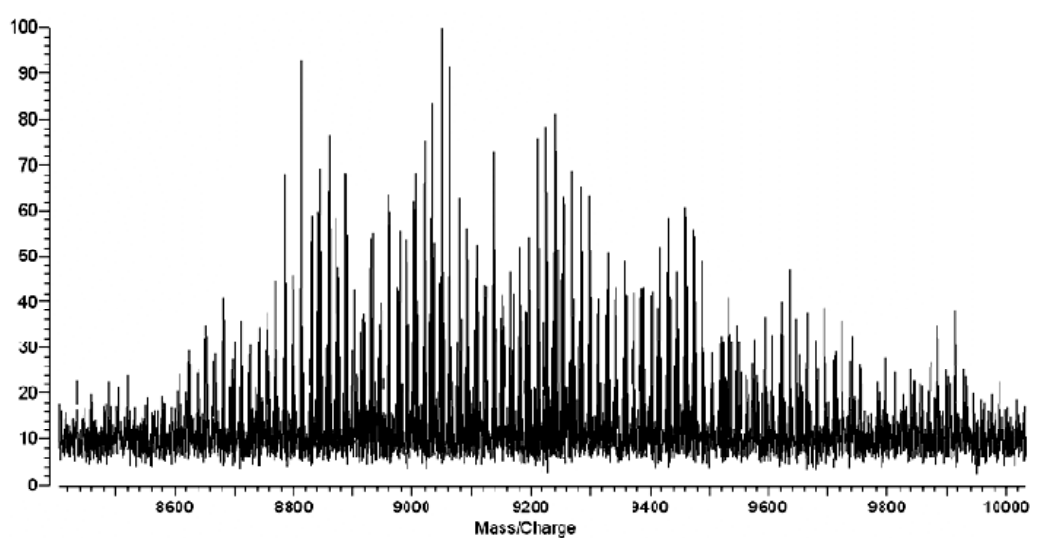

Figure 2. MALDI-FTMS of the EO-PO copolymer having a mass envelope from m/z 8300 to $\mathrm{m} / \mathrm{z} 9900$
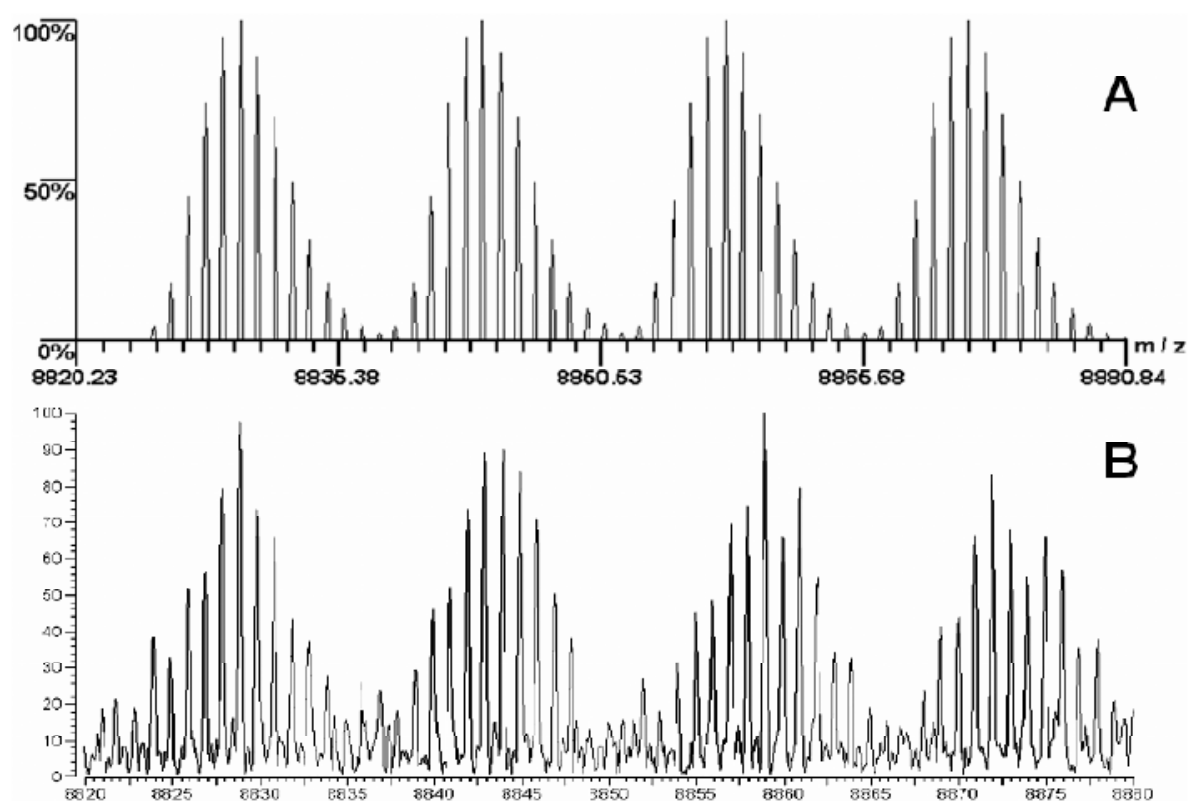

Figure 3. An expanded mass range of the MALDI-FTMS spectrum showing oligomeric and isotopic resolution:

The top (A) spectrum is the theoretical range and the bottom (B) spectrum is the experimental result

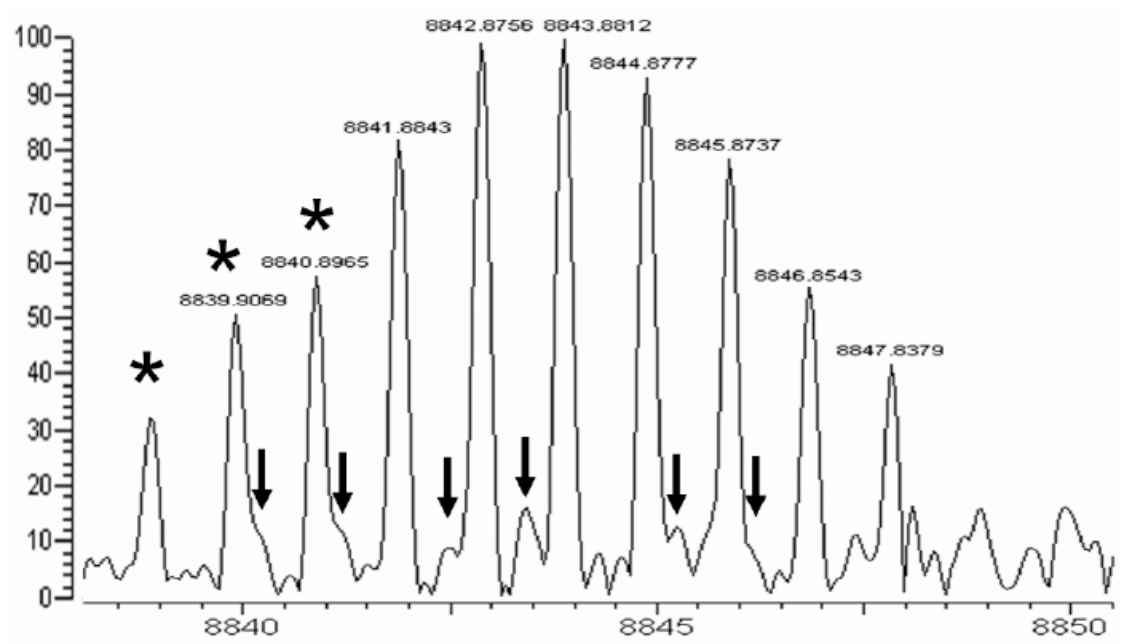

Figure 4. An isotopically resolved oligomer of the MALDI-FTMS spectrum. See text for explanation of the peaks with asterisks and arrows 


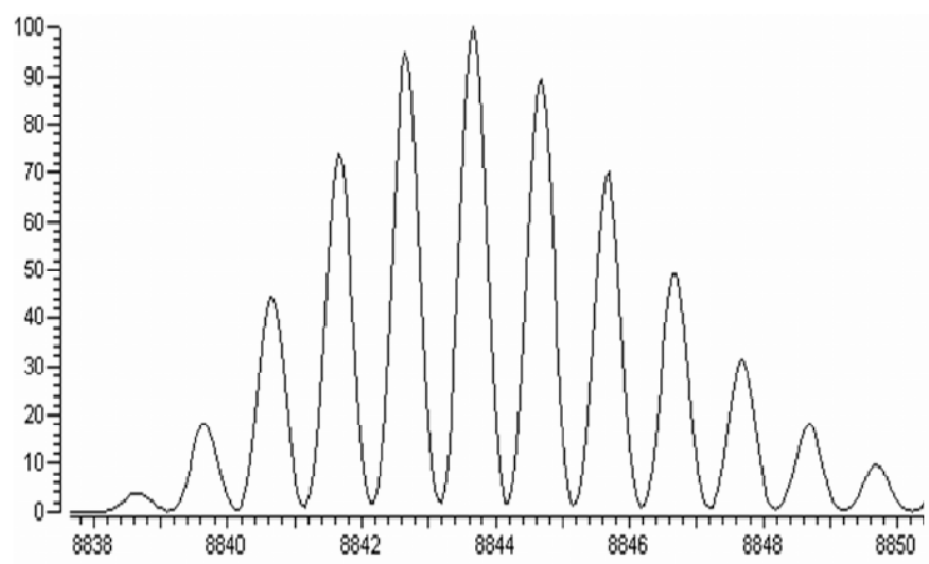

Figure 5. A theoretical isotopically resolved oligomer which corresponds to the experimental one shown in Figure 4

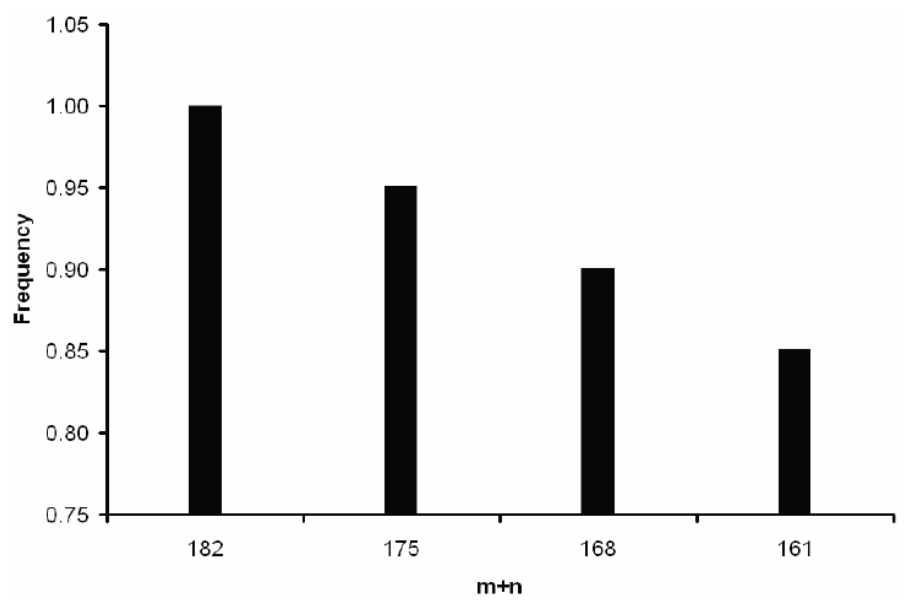

Figure 6. The most probable series of compositional combination of EO-PO segments

\section{Acknowledgments}

The authors gratefully acknowledge support from National Science Foundation grants CHE-00-91868, CHE-99-82045, and CHE-04-55134.

\section{References}

Alexandridis, P., \& Hatton, T. A. (1995). Poly(Ethylene Oxide)-Poly(Propylene Oxide)-Poly(Ethylene Oxide) Block-Copolymer Surfactants in Aqueous-Solutions and at Interfaces - Thermodynamics, Structure, Dynamics, and Modeling. Colloids and Surfaces a-Physicochemical and Engineering Aspects, 96(1-2), $1-46$.

Chen, R., Zhang, N., Tseng, A. M., \& Li, L. (2000). Effects of matrix-assisted laser desorption/ionization experimental conditions on quantitative compositional analysis of ethylene oxide/propylene oxide copolymers. Rapid Communications in Mass Spectrometry, 14(23), 2175-2181. http://dx.doi.org/10.1002/1097-0231(20001215)14:23\%3C2175::AID-RCM150\%3E3.0.CO;2-2

Chu, B. (1995). Structure and Dynamics of Block-Copolymer Colloids. Langmuir, 11(2), 414-421. http://dx.doi.org/10.1021/la00002a009

Dolan, R. A., \& Wood, T. D. (2004). Analysis of Polyaniline Oligomers by Laser Desorption Ionization and Solventless MALDI. J. Amer. Soc. Mass Spectrom., 15.

Gref, R., Minamitake, Y., Peracchia, M. T., Trubetskoy, V., Torchilin, V., \& Langer, R. (1994). Biodegradable Long-Circulating Polymeric Nanospheres. Science, 263(5153), 1600-1603. http://dx.doi.org/10.1126/science. 8128245 
Hamley, I. W. (1998). The Physics of Block Copolymers. New York, N. Y. : Oxford University Press.

Hanton, S. D. (2001). Mass Spectrometry of Polymers and Polymer Surfaces. Chem. Rev., 101, 527-570. http://dx.doi.org/10.1021/cr9901081

Jaber, A., \& Wilkins, C. L. (2005). Hydrocarbon Polymer Analysis by External MALDI Fourier Transform and Reflectron Time-of Flight Mass Spectrometry. J. Amer. Soc. Mass Spectrom., 16, 2009-2016. http://dx.doi.org/10.1016/j.jasms.2005.08.006

Jeong, B., Bae, Y. H., Lee, D. S., \& Kim, S. W. (1997). Biodegradable block copolymers as injectable drug-delivery systems. Nature, 388(6645), 860-862. http://dx.doi.org/10.1038/42218

Kalinoski, H. T. (1996). Chemical Analysis of Polyoxyalkylene Block Copolymers. In V. M. Nace (Ed.), Nonionic Surfactants: Polyoxyalkykene Block Copolymers (Vol. 60, pp. 31-66). New York, N. Y.: Marcel Dekker.

Kaufman, J. M., Jaber, A. J., Stump, M. J., Simonsick, W. J., \& Wilkins, C. L. (2004). Interference from multiple cations in MALDI-MS spectra of copolymers. International Journal of Mass Spectrometry, 234(1-3), 153-160. http://dx.doi.org/10.1016/j.ijms.2004.02.014

Li, S. M., Rashkov, I., Espartero, J. L., Manolova, N., \& Vert, M. M. (1996). Synthesis, Characterization, and Hydrolytic Degradation of PLA/PEO/PLA Triblock Copolymers with Long Poly(L-lactic acid) Blocks. Macromolecules, 29(1), 57-62. http://dx.doi.org/10.1021/ma9505311

Maciejczek, A., Mass, V., Rode, K., \& Pasch, H. (2010). Analysis of poly(ethylene oxide)-b-poly(propylene oxide) block copolymers by MALDI-TOF mass spectrometry using collision induced dissociation. Polymer, 5l(26), 6140-6150. http://dx.doi.org/10.1016/j.polymer.2010.10.031

Marie, A., Fournier, F., \& Tabet, J. C. (2000). Characterization of synthetic polymers by MALDI-TOF/MS: Investigation into new methods of sample target preparation and consequence on mass spectrum finger print. Analytical Chemistry, 72(20), 5106-5114. http://dx.doi.org/10.1021/ac000124u

Montaudo, M. S. (1999). Sequence constraints in a glycine-lactic acid copolymer determined by matrix-assisted laser desorption ionization mass spectrometry. Rapid Communications in Mass Spectrometry, 13(8), 639-644. http://dx.doi.org/10.1002/(SICI)1097-0231(19990430)13:8\%3C639::AID-RCM513\%3E3.0.CO;2-J

Montaudo, M. S. (2001). Determination of the compositional distribution and compositional drift in

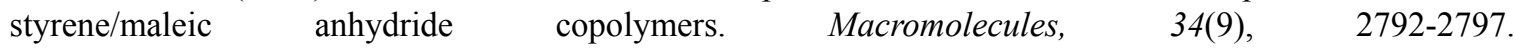
http://dx.doi.org/10.1021/ma0010231

Montaudo, M. S. (2002). Mass spectra of copolymers. Mass Spectrometry Reviews, 21(2), 108-144. http://dx.doi.org/10.1002/mas.10021

Montaudo, M. S., \& Samperi, F. (1998). Determination of sequence and composition in poly(butyleneadipate-co-butyleneterephthalate) by matrix-assisted laser desorption/ionization time-of-flight mass spectrometry. European Mass Spectrometry, 4(6), 459-465. http://dx.doi.org/10.1255/ejms.271

Nielen, M. W. F. (1999). Maldi time-of-flight mass spectrometry of synthetic polymers. Mass Spectrometry Reviews, $18(5)$,

309-344. http://dx.doi.org/10.1002/(SICI)1098-2787(1999)18:5\%3C309::AID-MAS2\%3E3.0.CO;2-L

O'Connor, P. B., \& McLafferty, F. W. (1995). Oligomer Characterization of 4-23 kDa Polymers by Electyrospray Fourier Transform Mass Spectrometry. J. Amer. Chem. Soc., 117, 12826-12831. http://dx.doi.org/10.1021/ja00156a021

Priorr, R. (1987). In J. Falbe (Ed.), Surfactants in Consumer Products (pp. 5-22). Heigelberg: Springer-Verlag.

Pruns, J. K., Vietzke, J.-P., Strassner, M., Rapp, C., Hintze, U., \& König, W. A. (2002). Detailed structural characterization of modified silicone copolymers by matrix-assisted laser desorption/ionization time-of-flight mass spectrometry. Rapid Communications in Mass Spectrometry, 16, 208-211. http://dx.doi.org/10.1002/rcm.568

Przybilla, L., Brand, J. D., Yoshimura, K., Rader, H. J., \& Mullen, K. (2000). MALDI-TOF mass spectrometry of insoluble giant polycyclic aromatic hydrocarbons by a new method of sample preparation. Analytical Chemistry, 72(19), 4591-4597. http://dx.doi.org/10.1021/ac000372q

Przybilla, L., Francke, V., Rader, H. J., \& Mullen, K. (2001). Block Length Determination of a Poly(ethylene oxide)-b-poly(p-phenylene ethynylene) Diblock Copolymer by Means of MALDI-TOF Mass Spectrometry 
Combined with Fragment-Ion Analysis. Macromolecules, 34, 4401-4405. http://dx.doi.org/10.1021/ma001676h

Rader, H. J., \& Schrepp, W. (1998). MALDI-TOF mass spectrometry in the analysis of synthetic polymers. Acta Polymerica, $49(16)$,

272-293.

http://dx.doi.org/10.1002/(SICI)1521-4044(199806)49:6\%3C272::AID-APOL272\%3E3.0.CO;2-1

Ryan, A. J., \& Stanford, J. L. (1989). In G. Allen \& J. C. Beviongton (Eds.), Comprehensive Polymer Science. Oxford, U.K.: Pergamon Press.

Schick, M. J., \& Fowkes, P. M. (1996). Nonionic Surfactants. In V. M. Nace (Ed.).

Schriemer, D. C., \& Li, L. (1996). Detection of high molecular weight narrow polydisperse polymers up to 1.5 million Daltons by MALDI mass spectrometry. Analytical Chemistry, 68(17), 2721-2725. http://dx.doi.org/10.1021/ac960442m

Servaty, S., Kohler, W., Meyer, W. H., Rosenauer, C., Spickermann, J., Rader, H. J., \& Wegner, G. (1998). MALDI-TOF-MS copolymer analysis: Characterization of a poly(dimethylsiloxane)-co-poly(hydromethylsiloxane) as a precursor of a functionalized silicone graft copolymer. Macromolecules, 31(8), 2468-2474. http://dx.doi.org/10.1021/ma970710y

Shi, S. D.-H., Hendrickson, C. L., Marshall, A. G., Simonsick, W. J., \& J., A. D. (1998). Idenification, Composition, and Asymmetric Formation Mechanism of Glycidyl Methacrylate/Butyel Methacrylate Copoymers of to $7000 \mathrm{Da}$ from Electrospray Ionization Ultrahigh-Resolution Fourier Transform Ion Cyclotron Resonance Mass Spectrometry. Anal. Chem., 70, 3220-3226. http://dx.doi.org/10.1021/ac980316d

Skelton, R., Dubois, F., \& Zenobi, R. (2000). A MALDI sample preparation method suitable for insoluble polymers. Analytical Chemistry, 72(7), 1707-1710. http://dx.doi.org/10.1021/ac991181u

Tanodekaew, S., Pannu, R., Heatley, F., Attwood, D., \& Booth, C. (1997). Association and surface properties of diblock copolymers of ethylene oxide and DL-lactide in aqueous solution. Macromolecular Chemistry and Physics, 198(4), 927-944. http://dx.doi.org/10.1002/macp.1997.021980402

Terrier, P., Buchmann, W., Cheguillaume, G., Desmazieres, B., \& Tortajada, J. (2005). Analysis of poly(oxyethylene) and poly(oxypropylene) triblock copolymers by MALDI-TOF mass spectrometry. Analytical Chemistry, 77(10), 3292-3300. http://dx.doi.org/10.1021/ac048193m

Trimpin, S., Grimsdale, A. C., Rader, H. J., \& Mullen, K. (2002). Characterization of an insoluble poly(9,9-diphenyl-2,7-fluorene) by solvent-free sample preparation for MALDI-TOF mass spectrometry. Analytical Chemistry, 74(15), 3777-3782. http://dx.doi.org/10.1021/ac0111863

Trimpin, S., Rouhanipour, A., Az, R., Räder, H. J., \& Müllen, K. (2001). New aspects in matrix-assisted laser desorption/ionization time-of-flight mass spectrometry: a universal solvent-free sample preparation. Rapid Communications in Mass Spectrometry, 15, 1364-1373. http://dx.doi.org/10.1002/rcm.372

van Rooij, G. J., Duursma, M. C., de Koster, C. G., Heeren, R. M. A., Boon, J. J., Schuyl, P. J. W., \& van der Hage, E. R. E. (1998). Determination of block length distributions of poly(oxypropylene) and poly(oxyethylene) block copolymers by MALDI-FTICR mass spectrometry. Analytical Chemistry, 70(5), 843-850. http://dx.doi.org/10.1021/ac970609r

Weidner, S. M., \& Falkenhagen, J. (2011). LC-MALDI-TOF Imaging MS: A New Approach in Combining Chromatography and Mass Spectrometry of Copolymers. Analytical Chemistry, 83(23), 9153-9158. http://dx.doi.org/10.1021/ac202380n

Wilczek-Vera, G. (1996). Individual Block Length Distributions of Block Copolymers of $\begin{array}{llll}\text { Polystyrene-block-Poly }(\alpha \text {-methylstyrene). } & \text { Macromolecules, } & 29, & \text { 4036-4044. }\end{array}$ http://dx.doi.org/10.1021/ma9516394

Wilczek-Vera, G., Yu, Y. S., Waddell, K., Danis, P. O., \& Eisenberg, A. (1999a). Analysis of diblock copolymers of poly(alpha-methylstyrene)-block-polystyrene by mass spectrometry. Macromolecules, 32(7), 2180-2187. http://dx.doi.org/10.1021/ma981594h

Wilczek-Vera, G., Yu, Y. S., Waddell, K., Danis, P. O., \& Eisenberg, A. (1999b). Detailed structural analysis of diblock copolymers by matrix-assisted laser desorption ionization time-of-flight mass spectrometry. Rapid $\begin{array}{lllll}\text { Communications in } & \text { Mass } & \text { 764-777. }\end{array}$ http://dx.doi.org/10.1002/(SICI)1097-0231(19990515)13:9\%3C764::AID-RCM557\%3E3.0.CO;2-9 
Yoshida, S., Yamamoto, S., \& Takamatsu, T. (1998). Detailed structural characterization of modified silicone copolymers by matrix-assisted laser desorption/ionization time-of-flight mass spectrometry. Rapid Communications in Mass Spectrometry, http://dx.doi.org/10.1002/(SICI)1097-0231(19980515)12:9\%3C535::AID-RCM191\%3E3.0.CO;2-8

Yu, D., Vladimirov, N., \& Frechet, J. M. J. (1999). MALDI-TOF in the Characterizations of Dendritic-Linear Block Copolymers and Stars, 32, 5186-5192.

Zoller, D. L., \& Johnston, M. V. (2000). Microstructures of butadiene copolymers determined by ozonolysis/MALDI mass spectrometry. Macromolecules, 33(5), 1664-1670. http://dx.doi.org/10.1021/ma991157i

\section{Notes}

Note 1. Orwa Jaber Housheya (aka, Arwah Jaber). 